\title{
Deinstitutionalization in the context of software exports policymaking in Costa Rica
}

\author{
Brian Nicholson ${ }^{1}$, Sundeep Sahay ${ }^{2}$ \\ ${ }^{1}$ Manchester Business School, Manchester, UK; \\ ${ }^{2}$ Department of Informatics, Oslo, Norway \\ Correspondence: \\ B Nicholson, Manchester Business School, Booth Street West, Manchester M15 6PB, UK. \\ Tel: + 44161275 4024; \\ Fax: + 44161275 4023; \\ E-mail: brian.nicholson@mbs.ac.uk
}

\begin{abstract}
This paper addresses deinstitutionalization from a longitudinal perspective. Drawing on the case of software exports policymaking in Costa Rica, it analyses deinstitutionalization, paying particular attention to formation of dissensus, understood as lack of unanimity on the value of an activity that is sufficient to destabilize institutional norms and activities. The role of cultural and political factors in deinstitutionalization or persistence is considered. Based on the empirical data, a framework for understanding political and cultural dynamics in deinstitutionalization is proposed.
\end{abstract}

Journal of Information Technology (2009) 24, 332-342. doi:10.1057/jit.2009.18

Published online 6 October 2009

Keywords: national software export policy; Costa Rica; deinstitutionalization

\section{Introduction}

$\mathbf{T}$ his paper focuses on policy formulation and implementation for software exports in the context of a developing country. This domain of software exports is regarded by many national governments and also international agencies such as the World Bank as an important enabler of economic growth (Heeks, 1999; Kambhampati, 2002; World Bank, 2002; Al-Jaghoub, 2004; Heeks and Nicholson, 2004). Software industry growth in India and also in other countries has been shaped by various policy initiatives (Ein-Dor et al., 1997, 2004; Kambhampati, 2002), such as favourable tax exemptions in Vietnam (Duong, 2004), the creation of Software Technology Parks in India (Arora et al., 2001), incentives for Foreign Direct Investment (FDI) in Ireland (O'Higgins, 2002), and venture capital support for military-oriented software products in Israel (Carmel and de Fontenay, 2004).

To analyse the context, process and their mutual linkages theoretically, we draw upon new institutional theory (DiMaggio and Powell, 1991; Scott, 2001). This examines how broad social and historical forces, ranging from explicit laws to implicit cultural understandings, affect and are affected by the actions of individuals and organizations (Orlikowski and Barley, 2001: 153). Within institutional theory, we especially focus on the notion of deinstitutionalization, which is of particular relevance to policymaking as it focuses on the process by which the legitimacy of an institutionalized practice erodes or discontinues (Oliver, 1992). The focus is on understanding the interplay between existing institutional conditions of software exports and how these shape the introduction of new policies. Policymaking frameworks (Heeks and Nicholson, 2004) and case studies of ICT industry planning (Ó Riain, 1997; O'Higgins, 2002; Al-Jaghoub and Westrup, 2003) demonstrate how software industry policymaking and implementation involves purposeful action towards the creation of new institutions, which necessarily involves suppressing existing ones to enable the shifting to new institutional forms, practices and rules.

Maguire and Hardy (2009) point out that there is a paucity of empirical studies of deinstitutionalization, particularly where analysis involves both 'outsider-driven' and 'insider-driven' deinstitutionalization. This paper contributes an empirical analysis of the process of deinstitutionalization, including both insider- and outsider-driven perspectives in the context of policymaking and implementation in the software exports sector in Costa Rica. By examining the role of political and cultural phenomena in relation to dissensus and the various 
countervailing forces of consensus, it contributes to our understanding of deinstitutionalization and also 'the staying power of institutional arrangements' (Currie, 2009: 75) and 'mechanisms that serve to prevent dissipation and eventual deinstitutionalization' (Dacin and Dacin, 2008: 348).

The paper is organized as follows: we begin with an examination of current literature and theoretical discussion drawn from institutional theory focusing on processes of deinstitutionalization. This is followed by a description of the methodology and the research setting. We continue with the case analysis of the interplay of the processes of deinstitutionalization, with a particular focus on the role of dissensus within and between subcultures, considering both insider and outsider influences. We conclude with a discussion on the contributions to theory and practice.

\section{Deinstitutionalization, organizations and IS research}

In a seminal paper, Oliver (1992) defines deinstitutionalization as

the process by which the legitimacy of an established or institutionalized organizational practice erodes or discontinues ... the delegitimation of an established organizational practice or procedure as a result of organizational challenges to or the failure of organizations to reproduce previously legitimated or takenfor-granted organizational actions (564)

There have been various studies in the domain of organization studies that have drawn upon the concept of deinstitutionalization to analyse change processes, specifically the conditions, external and internal, that constrain or enable deinstitutionalization (e.g. Roberts and Greenwood, 1997; Chizema and Buck, 2006; Erakovic and Powell, 2006; Koene, 2006; Rorrer, 2006; Windels and Christiaens, 2006; Dacin and Dacin, 2008). However, in IS research, the use of deinstitutionalization is limited even though there is a growing interest in institutional theory (Noir and Walsham, 2007; Currie, 2009). The early contribution of King et al. (1994) into institutional impact on innovation has been used in subsequent IS studies (e.g. Silva and Figueroa, 2002) to understand the regulative aspect of institutions (government authorities, international agencies, trade associations), and how these become 'part of the furniture' (Silva and Backhouse, 1997), until a breakdown occurs.

The dominant focus of IS researchers has been on using institutional theory to understand persistence (as compared with change), however there are some exceptions such as Robey and Boudreau's (1999) work on the 'logic of opposition'. They caution that 'a researcher guided by institutional theory should be impressed by the difficulty of changing institutionalized practices' (177). Another more change-focussed account is provided by Robey and Holmstrom (2001) in their dialectic analysis of the use of information technology to support the governance process in the municipal organization of Umea, Sweden, examining forces both promoting and opposing social change. Avgerou (2002) emphasizes the inter-linkages between organizations through the concept of a diverse organizational field described by DiMaggio and Powell (1983) as 'those organizations that, in the aggregate, constitute a recognized area of institutional life: key suppliers, resource and product consumers, regulatory agencies, and other organizations that produce similar services or products' (43). Members of an organization field partake of a common meaning system, usually under equivalent regulatory systems, and whose participants interact more frequently and fatefully with one another than with actors outside of the field (Scott, 1994: 207-208). The contradictions resulting from the inter-linkages in the field can create dissensus and challenge the existing consensus, thus enabling processes of deinstitutionalization.

Following this overview of the theoretical concept of deinstitutionalization and its use in organization and IS research, the next section outlines our use of this concept as an analytical lens in the context of policymaking for the software industry.

\section{Deinstitutionalization in the context of software industry policymaking}

Oliver (1992) presents a model of the process of deinstitutionalization that involves an erosion, deterioration and eventual discontinuity in the acceptance and use of a particular institutionalized practice. This erosion takes place due to political, functional and social pressures, conceptualized as the 'antecedents of deinstitutionalization' summarized in Figure 1. If these pressures lead to decline in the institutional practice then this is termed as dissipation. Pressures that accelerate or impede the rate of dissipation are referred to as entropy and inertia, respectively. If the institutionalized practice is directly challenged then rejection may occur rather than the more gradual dissipation.

In Oliver's model, pressure for deinstitutionalization may emanate from political sources when institutions are contested, reflecting an underlying dissensus. In such situations, pressure for deinstitutionalization involves the commitment of resources and conflict between those who want change and those who do not, and institutions are maintained only as long as integrative forces counteract disintegration. Functional pressures for deinstitutionalization may be the consequence of changes to the perceived utility or technical instrumentality of practices on economic grounds and for reasons of accommodating varying political interests and changing environmental conditions. Social pressures for deinstitutionalization arise with normative fragmentation and the breakdown of cultural unanimity in shared meanings and practices.

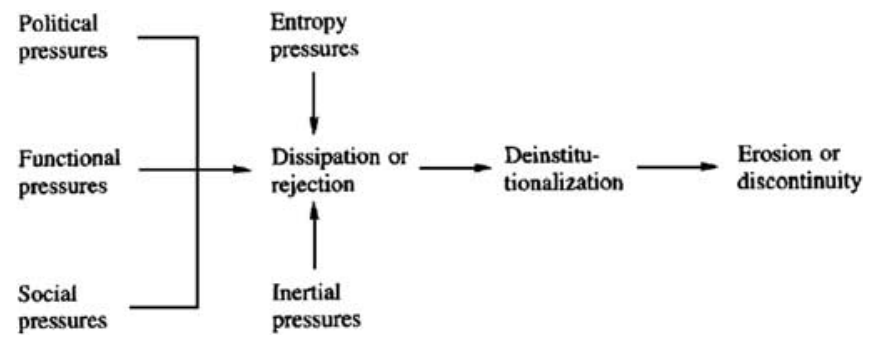

Figure $1 \mathrm{~A}$ deinstitutionalization framework.

Source: Oliver (1992). 


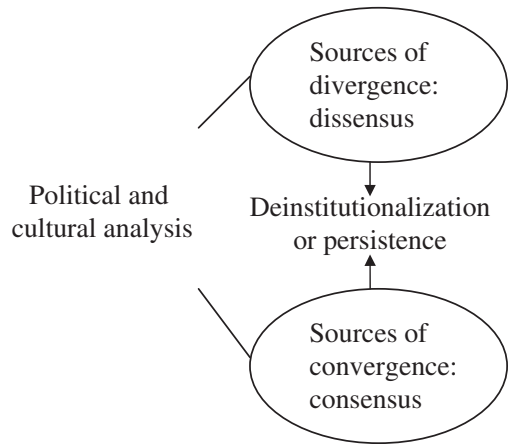

Figure 2 Theoretical framework.

In our adoption of the theory of deinstitutionalization, we seek to analyse conditions that can trigger and counter deinstitutionalization processes in national policy for software exports in Costa Rica. Our theoretical framework is schematically depicted in Figure 2, and then discussed.

Software exports policymaking takes place in a particular 'organization field' understood as sector, niche, or market, involving multiple organizations, individual actors and associated institutions. For our analysis, we draw upon concepts of dissensus and consensus viewed through a political-cultural lens. Consensus and dissensus have been described by Oliver as follows:

Since consensus or reciprocal typifications among actors on the meaning, value and validity of an organisational form or activity is a fundamental condition of ongoing conformity to institutional practices (Berger and Luckmann, 1967; Meyer and Rowan, 1977; Scott, 1987), the development of political dissensus or conflicting interests that disrupt the unanimity of agreement among organisational members on the value of a particular practice will be a critical antecedent to deinstitutionalization. (569)

Calling explicitly for a political-cultural analysis, Oliver argues that

organizations often possess 'competing value systems that create a mosaic of organizational realities rather than a uniform corporate culture' (Morgan, 1986: 127). A political-cultural analysis of institutionalized activities may help to determine how dissensus creates institutional adjustments or erosion, and how negotiation processes may create consensual perceptions. (582)

Farjoun (2002) describes the dialectic between dissensus and consensus in relation to convergent and divergent forces. While convergent forces shape consensus, such as actors' interests and functional utility, opposing divergent forces towards dissensus challenge them, representing a dialectic interplay leading to persistence or deinstitutionalization. Analysing this interplay is a complex task, leading Oliver (1992) to pose the following question as a challenge for future research:

if institutionalized activities are behaviours that reflect 'common understandings' of legitimate behaviour, what degree of consensus is enough to sustain an institutionalized practice? (581)

Political dissensus is understood as lack of unanimity among stakeholders within the organizational field that can destabilize existing institutional norms and activities. Oliver (1992) posits that political pressures for deinstitutionalization, such as a performance crisis, may erode institutionalized activities, creating the potential for heightened internal conflict and breakdown of shared interpretations of appropriate behaviour. Such a crisis may also cause norms of cooperation to move towards self-interested gains and individual protection, which may challenge the interests of existing stakeholders. These internal organizational dynamics may be also influenced by environmental conditions, such as if current performance is seen to be inadequate relative to competitors.

Concepts related to culture can provide further insights into responses to pressures that may occur within an organizational setting. Culture, broadly understood as shared meaning, understanding and sense making, has a long history of inclusion in IS research (Leidner and Kayworth, 2006) including in the context of institutional analysis (Noir and Walsham, 2007). An explicit analysis of culture has the potential to deepen our understanding of the sources and dynamics of dissensus and consensus in relation to deinstitutionalization. Pressures for deinstitutionalization arise with the breakdown of cultural unanimity in shared meanings and practices, contributed to by various social pressures including greater diversity, mergers, high turnover or new leaders, leading to loss of cultural consensus and the creation of new norms and practices. Such disruptions call attention of organizational participants and exert social pressures on the organization to redefine its formal and informal institutions. The State through new laws (example for safety and pollution) can also create pressure and new demands for deinstitutionalizing existing practices.

Culture is pertinent to the continuation or not of shared meanings, sense making and routines of behaviour and the maintenance of the legitimacy of an institution due to actors' perceptions of its social desirability and continued acceptance. We draw on Rodrigues' (2006) analysis of subcultures in our analysis of dissensus, consensus and their contribution to deinstitutionalization. Maguire and Hardy (2009) describe 'defensive institutional work' that comprises purposive action aimed at countering 'disruptive institutional work'. Defence or disruption may emerge from purposeful activity of subcultures or be influenced by national cultural tendencies (Biesanz et al., 1998; Walsham, 2002). Rodrigues argues that subcultures mediate and protect the interests of their members and adherents who can form alliances to further advance their interests. For instance, a subculture can over time become dominant and subsequently be advanced as an organization's corporate culture. A subculture may become a counterculture and use political tactics to oppose and undermine competing subcultures. To make sense of cultural effects on dissensus and consensus, the subculture approach emphasizes heterogeneity, and continuous negotiation and redefinition over time (Walsham, 2002). 
In summary, our theoretical perspective is built around deinstitutionalization, analysing both cultural and political conditions, arising from both internal and external forces that shape consensus or dissensus within the organizational field under study.

\section{Methodology}

The authors were invited in 2002 by the representatives of Costa Rica's Inter American Development Bank-funded software industry development organization 'Prosoftware'. We participated along with Cegesti, a San José-based notfor-profit consultancy organization, in developing the Costa Rican national policy for enabling software exports. Our participation can be conceptualized within an action research framework (Checkland, 1991; Baskerville and Wood-Harper, 1996), as our focus was explicitly on the formulation of the strategy and its subsequent implementation. The cycle of intervention and reflection is represented in Figure 3.

The methodology (M) comprises problem definition, analysis and action stages, including planning for the empirical work and a literature search of the Costa Rican software industry. This enabled identification of the current situation of the industry in terms of size, number of firms and revenues, the key stakeholders, and the particular technological and geographical orientation of the industry. The next phase of the analysis took place during August and September 2003. Interviews with government policymakers, university teachers and researchers; financiers and bankers, software industry executives and managers of the software firms enabled us to diagrammatically 'map' the stakeholders and their formal and informal influences on the formulation and implementation of a national software exports. This was done using Checkland and Scholes (1999) rich picture technique.

Interviews were semi-structured and focussed on understanding the respondent's background, interests and perceived influences with respect to software exports. Respondents were asked to consider the historical, present or future issues relevant for the development of a policy

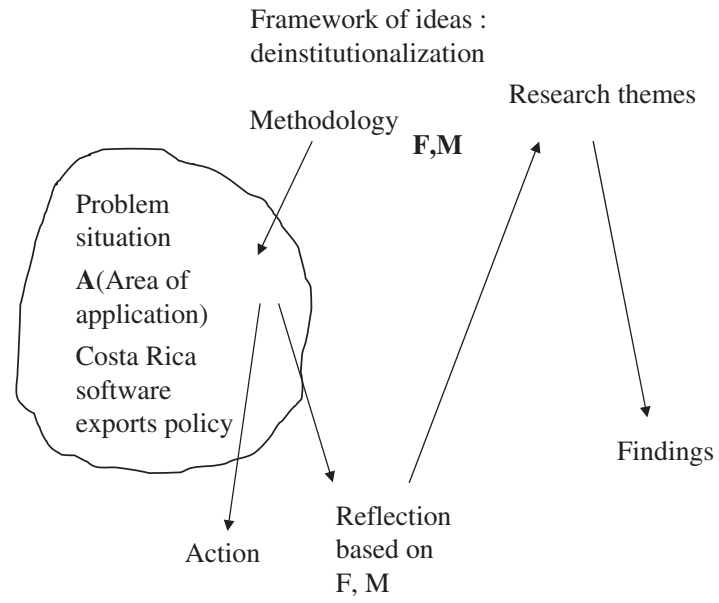

Figure 3 Cycle of action research.

Source: Adapted from Checkland (1991). and their level of commitment towards change. Two focus group sessions were held, attended by approximately fifteen stakeholders, respectively. The first involved representatives from the private sector (software firms, banks and venture financiers, software export promotion organizations) and the other with university staff (lecturers, researchers, university bureaucrats). In these focus groups, discussion focussed on issues involving multi-stakeholder relationships such as university-private sector linkages, and relations between small and medium firms with financial organizations. A large national-level workshop was conducted on the topic of global software trends, which helped to create awareness about exports and to gain stakeholder commitment and suggestions on the 'way forward'. The interviews were mostly conducted in English and when in Spanish, a local interpreter was used. For the national-level workshop, professional simultaneous translation was provided. Table 1 summarizes the various data collection sources.

Various secondary data sources, such as industry reports, company reports, brochures, websites and industry statistics from the software association database were analysed to flesh out our understanding of the institutional context. The rich picture helped to trace the inter-linkages between the various stakeholders and identify problematic themes in building such links and potential influences on software exports.

In the action phase, four 'task force groups' ${ }^{1}$ comprising members from different stakeholder organizations were created, each addressing specific problems, and assigned the responsibility to design the solutions and implementation plan. For example, a task force group with a university and software firm membership aimed to identify the measures needed to strengthen university and private sector linkages in support of software export processes. These task force groups were provided with support from the consultants, including resources such as information on best practices from other countries. They were asked to develop specific recommendations on short- and mediumterm action required, and to suggest indicators to measure progress. There were continuous revisions made to the plans, in line with Checkland and Scholes (1999) emphasis that policy formulation is ongoing, continuous and iterative, shaped by individuals and groups who have a stake in the process.

Data analysis involved a process of extensive discussion between the authors and the various stakeholders, in which we shared with them our opinions and findings, and received their criticism and comments. A report was presented in 2003 to Prosoftware, the organization that

Table 1 Summary of data collection sources

\begin{tabular}{lcccr}
\hline $\begin{array}{l}\text { Data collection } \\
\text { mechanism }\end{array}$ & $\begin{array}{c}\text { August- } \\
\text { September } \\
2003\end{array}$ & $\begin{array}{c}\text { July- } \\
\text { August } \\
2005\end{array}$ & $\begin{array}{c}\text { August } \\
2006\end{array}$ & Total \\
\hline Interviews (co-present) & 18 & & 6 & \\
Interviews (telephonic) & & 4 & & 28 \\
Focus Groups & 2 & & & 2 \\
Workshops & 4 & & \\
\hline
\end{tabular}


commissioned the study, and this provided the bedrock for the articulation of the national policy. Reflections took place in the process of writing in academic papers, with reviewer feedback contributing to the analysis of the themes of the case. Our continued reading of the academic literature (especially related to institutional theory) and discussions between ourselves and with colleagues led to the current framing of the paper around deinstitutionalization.

The 'cycles of reflection' continued over time, and in mid-2005, nearly 2 years on from our initial actions, four audio conferencing interviews were conducted. These interviews were facilitated by Cegesti and involved some key members of the software industry organization. Furthermore, one of the authors returned to Costa Rica in March 2006 to present at a software industry conference, part of which was dedicated to reflection on progress with the software export promotion policy. During this visit, six further interviews were undertaken with key stakeholders (software firm managers, software association executives and financiers), which updated us with events and the perspectives on effectiveness of the policy and identification of further future planned measures. The 2-year gap between interviews allowed sufficient time for the policy process to have had an impact. We maintained informal email and telephone calls during this interim period with our colleagues in Cegesti, who kept us informed of events.

\section{The Costa Rican software industry}

The Costa Rican software sector gained significant global publicity when the IT giant Intel established a development unit in San Jose, enabled through the direct involvement of the Costa Rican President (Ketelhoehn and Porter, 2002). According to Camtic (2006) market research, in 2005 there were 150 software development companies, $91 \%$ of these were micro, small and medium sized. Applications 'for and about the Internet' and 'administration and engineering' were the prominent application domains. In 2005, the sector reported revenues of US\$173 million and employed 4800 staff. Figures in 2005 showed a reduction over the previous year in production and banking software and an increase in customized application development. Thirty percent of the software production was exported, including $\$ 71$ million to Central America (reduced from $60 \%$ in 2004 to $40 \%$ in 2005), and exports to the USA, which increased from $13.3 \%$ in 2004 to $22 \%$ in 2005 .

The organizational field conceptualized by the authors included a range of heterogeneous actors ranging from the Minister of Science and Technology, to university researchers and faculty, international aid agencies and also local banks and venture capital firms. Also of importance were the private sector IT firms, and various government agencies responsible for different activities related to software exports such as the export promotion bureau (Procomer), the organization responsible for FDI (Cinde) and the telecommunication services provider (ICE). We as researchers and facilitators of this process were part of the outsider-driven deinstitutionalization efforts.

Two contrasting episodes are described below: the first involves deinstitutionalization and demonstrates the process of erosion in the acceptance and use of a particular institutionalized practice. Dissensus, although initially suppressed by the dominant subculture, was subsequently mobilized through various external and internal forces contributing to the destabilization of existing norms and creation of new institutions. In the second episode, deinstitutionalization did not ensue. Mobilization and escalation of dissensus did not occur and existing institutions persisted. We analyse these two episodes through a political-cultural lens around dissensus and consensus and their potential in activating or suppressing processes of deinstitutionalization. The two episodes elaborate on two key organizations and their institutions: the national software industry association (Caprosoft), positioned as the key agent for change, and Cinde, the agency responsible for promoting FDI investments in Costa Rica including in the software sector.

\section{Episode 1: dissensus and deinstitutionalization at Caprosoft}

Caprosoft membership comprises the senior management of many of the software development firms in Costa Rica, excluding call centres and other IT-enabled services (ITES) firms. There was an inherent unwillingness to change among some of the Caprosoft members, even though the sponsors of the programme (IADB) had identified Caprosoft as the key change agent with respect to creating the software export policy. There was a dominant subculture within Caprosoft comprising owners of the relatively large software firms, who promoted consensus for maintenance of the existing institutions in the organization and a continued focus on serving domestic markets where they perceived positions of dominance. This subculture perceived the role of Caprosoft as a social networking organization akin to a 'wine drinking club'. There was underlying dissensus among some of the other members, mainly owners of the smaller firms, who saw engaging in software exports as a way to create a level playing field and expand their operations. Through our outsider-driven action research efforts, we tried to bring forth this dissensus and make it more visible, and then create sufficient momentum that could lead to the creation of a counter subculture, which subsequently could lead to deinstitutionalization of the dominant institution that favoured a domestic rather than export focus. We further elaborate on this process below.

The IADB funding for strategic software exports planning in Costa Rica designated Caprosoft as the agent for change in the policy process. A key recommendation of the policymaking task force group examining the role of Caprosoft was the creation of a new organization with a wider formal constitution to include both the local and foreign activities of the software industry, as opposed to its currently primarily local mandate, and also to open membership to ITES providers (call centres and business process outsourcing firms). The successful Indian example (of NASSCOM) was described to the members to emphasize the benefits of such an extended focus, including lobbying the government for more benefits to the industry. Such external examples were drawn upon to counter the 'wine drinking club culture' of Caprosoft members and their desire for the maintenance of the status quo. The large software firm players constituted a dominant subculture in Caprosoft and perceived themselves as 'big fish in a small 
pond'. Serving the stagnant domestic Costa Rican market was adequate for them to maintain their existing comfortable lifestyle. International expansion in a strongly competitive market was not seen as critical to their survival, and on the contrary was viewed as a threat that could even undermine their comfortable existence. The shared sense making of this subculture was reinforced by broader cultural characteristics in Costa Rican society, described to us by a venture capital financier as follows:

Here (in Costa Rica) people will be happy to earn a good salary, have a nice car, a nice house, and have their children in a good school and owning $100 \%$ of their companies. And that's it. So there is a limited level of preference of risk taking or ambition.

Initial attempts by the authors, Cegesti and the task force group to disrupt institutions and to broaden the mandate of the association membership to include export-focussed ITES firms and potentially create a counter-subculture were resisted. Defensive institutional work of the existing dominant 'wine drinking club' subculture vetoed this move, legitimizing their arguments by expressing cynicism among insiders over the IADB financial aid strategy describing it as 'a legacy of USA's historical attempts to control (both through means of politics and violence) several of the Central and Latin American countries such as in neighbouring Honduras, Nicaragua, Panama, Cuba and El-Salvador'.

The task force members faced the difficult situation of generating dissensus opposed by a dominant subculture that supported the status quo and paradoxically were responsible for the engagement in software exports. Decisive outsider-driven deinstitutionalization was impeded by a cultural tendency among Costa Ricans described to us by an interviewee (a Costa Rican software industry venture capitalist) to 'avoid offending each other'. Biesanz et al. (1998) has written on this topic:

In their relations with others, $\operatorname{Ticos}^{2}$ want above all to 'Quedar bien' - to get along and make a good impression in an encounter, to appear amiable. It is easier to promise to do something 'ahorita' (in a little while) or 'mañana' and thus avoid possible friction at the moment than it is to tell someone that it cannot be done soon or perhaps ever. (8)

A senior Caprosoft member attributed this tendency to avoid conflict to the relatively small size of the country where 'there was always the distinct possibility of meeting someone where you may need a favour in return'. He said:

Costa Rica is so small. It's so small that nobody can take the luxury of confronting anybody, because in no time you will meet again, in other circumstances, most likely the situation will be the other way around. So when you come to live here, you want no enemies. Confrontation is just not worth it ... so people prefer to manage relationships.

This cultural feature of avoiding confrontation is also reflected in the Costa Rican constitution that abolished its army in 1949, and established the reputation of a peaceful country. President Oscar Arias was awarded the Nobel Peace Prize for his role in ending the wars in El-Salvador and Nicaragua. Costa Rica is widely perceived as a peaceful haven within a relatively violent Central American neighbourhood. Furthermore, the dependence of the national economy on tourism also provides an economic rationale of maintaining a peaceful environment. Costa Ricans boast that their President can mingle freely without security within a crowd. Biesanz et al. (1998) posit that the result of conflict avoidance is prolonged decision making:

Decision making a la tica means constant bargaining in an effort to avoid conflict, even though the problem may not really be resolved. Decisions are postponed indefinitely and once made may never be implemented. A common term of phrase in Costa Rica for this is palanganeo evoking an image of riding the waves unsteadily in a palangana or basin tilting from side to side, getting nowhere. (7)

The defensive institutional work of the dominant subculture in Caprosoft coupled with wider cultural tendencies offer an interpretation of why the outsider task force groups were not able to generate sufficient dissensus, at least in the early stages of the efforts. However, over time, a counter-culture emerged led by three key individuals, a North American expatriate and two Costa Ricans with existing North American software operations, who were promoted to the board of Caprosoft in 2005. These individuals provided the impetus to mobilize insider-driven deinstitutionalization by generating dissensus regarding the domestic focus and restricted mandate for membership. The counter-subculture was supported by Alexander Mora, a founder and former Caprosoft chairman. As well as being a highly respected senior industry leader who was acting as a champion for change, Mora had been previously invited for government advisory posts and maintained networks with ministers and senior bureaucrats. External exemplars supported dissensus when several members of the opposing subculture travelled to India to visit NASSCOM and were convinced of the appropriateness of the Indian model for the Costa Rican situation. A tipping point was reached when at a crucial meeting in 2005, in line with recommendations from the task force, Caprosoft's formal rules and constitution were eventually rewritten to include in their membership the ITES call centres and back office processing firms. In line with this revised mandate, the new organization was renamed Cámara Costarricense de Tecnología de Información y Comunicación (Camtic) in 2005. As more members of the ITES group became members of Camtic, dissensus on the Caprosoft institutions was heightened, further helped by the resignation of members from the earlier dominant subculture.

In summary (see Table 2), the forces of dissensus relating to the deinstitutionalization of Caprosoft were both insider and outsider driven. Outsiders included the IADB whose funding initiated the process, furthered by the authors and Cegesti who created the task force groups. External pressures for deinstitutionalization were reinforced when 
Table 2 Timeline showing dissensus and consensus at Caprosoft

\begin{tabular}{|c|c|c|c|c|c|}
\hline & 2002 & 2003 & 2004 & 2005 & 2006 \\
\hline $\begin{array}{l}\text { Sources of } \\
\text { dissensus }\end{array}$ & & $\begin{array}{l}\text { Outsider-driven } \\
\text { deinstitutionalization } \\
\text { efforts: consultants } \\
\text { and task group } \\
\text { intervention. }\end{array}$ & $\begin{array}{l}\text { Disruptive } \\
\text { institutional work: } \\
\text { attempted entry of } \\
\text { new firms to the } \\
\text { Caprosoft } \\
\text { membership. }\end{array}$ & $\begin{array}{l}\text { New Caprosoft board } \\
\text { members supported } \\
\text { by Alexander Mora. } \\
\text { Creation of dissensus } \\
\text { by disruptive } \\
\text { institutional work } \\
\text { promoting benefits } \\
\text { of admission of ITES } \\
\text { firms. } \\
\text { Emergence of a } \\
\text { counter subculture. } \\
\text { Resignation of key } \\
\text { members of } \\
\text { previously dominant } \\
\text { subculture. }\end{array}$ & \\
\hline $\begin{array}{l}\text { Sources of } \\
\text { consensus }\end{array}$ & $\begin{array}{l}\text { Caprosoft a } \\
\text { 'wine drinking } \\
\text { club'. }\end{array}$ & $\begin{array}{l}\text { Costa Rican cultural } \\
\text { tendency for conflict } \\
\text { avoidance and } \\
\text { indecisiveness. }\end{array}$ & $\begin{array}{l}\text { Dominant subculture } \\
\text { members defensive } \\
\text { institutional work: } \\
\text { sustain consensus } \\
\text { and veto entry. }\end{array}$ & & $\begin{array}{l}\text { Counter culture } \\
\text { becomes dominant } \\
\text { culture. } \\
\text { Revised mandate of } \\
\text { Camtic. }\end{array}$ \\
\hline
\end{tabular}

resources showing exemplars from external contexts (such as India) were provided and widely circulated. Insiderdriven disruptive institutional work generated dissensus, emanating mainly from the smaller players in Caprosoft who represented the excluded ITES sector and saw a 'window of opportunity' to express themselves in the ongoing efforts to reform Caprosoft. The promotion of three such members to the board and the resulting resignation of some of the 'old guard' enabled the deinstitutionalization. Through this, the contradiction in the role of Caprosoft of initiating change while still maintaining parochial interests could be seen to be resolved, at least for the present.

The contest between the 'old' and the 'new' subcultures was largely localized within Caprosoft, but dissensus could be inculcated by the counter-subculture in the organizational field between actors with shared meanings, which mobilized to act in unison. The key insiders from the counter-subculture who were raised to the board negotiated a position to persuade colleagues of the benefits of deinstitutionalization, thus challenging the status quo. Their own personal global interests were supported by a senior political figure. Concerted action by the outsider task force groups who were armed with knowledge from other contexts, helped in this process of mobilizing and voicing opposition to the legitimacy of existing institutions, raising dissensus to sustain rejection and deinstitutionalization. A summary of the events is provided in Table 2.

\section{Episode 2: consensus and persistence at Cinde}

A key organization in development of the software industry and exports was Cinde, the formal mandate of which is to promote FDI into Costa Rica. In the resources provided by the consultants to the relevant task force group, functional pressure for deinstitutionalization was reinforced when emphasizing how Ireland's strategy of promoting growth of the software industry with targeted FDI had been crucial (Ó Riain, 1997; O’Higgins, 2002).

The Costa Rican process of stimulating FDI was problematic for at least two reasons. One, it was uncoordinated, favoured foreign firms and the local industry was excluded in the process of FDI decision making. Local software firms voiced complaints that they were not made aware of Cinde's attempts to target foreign software industry firms for FDI, and Cinde was seen to play a unilateral role. While some of the exclusion of local firms from FDI decisions could have been deliberate, respondents informed us that it also reflected poor planning and organization between the firms themselves. Biesanz et al. (1998) posit that there is a dislike of formal planning in Costa Rica reinforced by a tendency to promote individualistic rather than group-oriented behaviour, reflected in the widespread use of the phrase 'Mmmmmimporata a mi?' (what does it matter to me?). This tendency to shrug off responsibility and justify lack of involvement with broader social issues also reflects a tendency towards distrust of others. Further, they write:

Rather than join with others to demand better bus services, Costa Ricans would be more likely to buy a car or motorcycle. Rather than cooperate with neighbours to prevent burglaries, there is a more generalised tendency to hire private security and buy guns (287).

The second reason was structural, the small size of the local firms contrasted with the large size of the typical global multinational FDI entrant. Based on higher salaries and the glamour of the multinational corporation (MNC) image, Intel was able to recruit trained software staff from local firms. The relatively small size of the Costa Rican 
national pool of software staff contributed to magnify the negative effects of Intel's entry, by enabling a 'local brain drain' from local firms to the MNC. We were given an example of the effects of relatively small yearly graduate output when Boeing wanted to set up a technical help line call centre operation requiring 500 people, but later decided to set up in Colombia since the Costa Rican education system did not guarantee required number of inputs into their workforce.

Deinstitutionalization of Cinde did not ensue for two interconnected reasons. First, Cinde is subject to private (not public) governance and primarily responsible to shareholders, without being subject to any direct government controls. Criteria for performance were based primarily on increasing the levels of FDI and there was no performance indicator that assessed impact locally of FDI. Second, the measure of performance of increasing FDI levels was directly correlated to maximizing size of the investing firms, which adversely impacted smaller local firms.

Through 2005 and 2006, despite considerable disruptive institutional work exerted by the task force groups in meetings and through other lobbying activities, the formal Cinde institutions were never deinstitutionalized and an independent mandate persisted. In the task force meetings, we observed Cinde participants 'going through the motions' of being present without genuinely engaging in framing measures towards change. Task force members described Cinde's participation as 'token' and 'representing a political act' since this entire process had been mandated by the Minister of Science and Technology, whose political will they could not easily rebuff. Token presence and political inaction were important aspects of defensive institutional work that contributed to sustaining the consensus for the Cinde institutions. Defensive institutional work prevented dissensus being magnified beyond the task force groups to involve other sectors, which could lead to accumulation of interests and deinstitutionalization.

The legitimacy of Cinde institutions was reinforced by the interests of their private shareholders to support their financial stake and they thus opposed change in the constitution, aims and objectives of the organization when this was raised at internal Cinde meetings. At a macrolevel, Cinde institutions are reflected in the neoliberal capitalist agenda of Costa Rican economic policy focussing on free markets that remained dominant to the socialist economic policy agenda of providing protection to the local software industry.

This position remained unchanged from 2003 to 2006, and several new and large MNCs made FDIs through subsidiaries in Costa Rica, and contributed to the loss of staff from local software firms. While there was dissensus from local software firms expressed in task group discussions and a heated debate at the Camtic industry conference in 2006, it tended to be localized and uncoordinated. A senior Camtic member told us in an interview in 2006:

The companies come in here and set up shop and hire people. That doesn't mean that any local companies are part of it. That's my point. Yesterday we had news that
Fujitsu is setting up a high tech call centre with 500 people, $\$ 5$ million. And we hear some of that every month.

Some MNCs such as Hewlett Packard increased their capacity by employing local staff and setting up offshore outsourcing operations from the USA. A bidding war between major firms such as Sykes and Proctor and Gamble to poach staff from each other led to increased salaries, which could not be matched by the local industry. A senior Cinde official recognized the problem:

Sykes, IBM or Hewlett-Packard or Intel, they have a different type of operation by definition, but they are demanding the same human resources (as the software firms).

In 2006, higher education and other training colleges expressed their lack of capacity to provide the necessary human resources to meet the fast growing demand for skilled IT staff. Local firms were unable to scale their operations and recruit from neighbouring Central American countries due to formal restrictions on visas and work permits. Inability to afford the increased salary took many to the brink of closure. A senior Camtic member explained:

The only way for these local companies to compete is to be able to make similar salary offers like these. And the only way to do that is if they do work for clients that also pay them well. And that won't happen with local companies working with local customers.

In summary, while there was a clear contradiction between the mandate of Cinde and the interests of the local software industry, adequate dissensus could not be generated to create the impetus for deinstitutionalization. A history of lack of disruptive institutional work to lobby for change was reinforced by cultural tendencies towards individualistic behaviour. The outsider task force group could not generate sufficient dissensus within insiders at Cinde, who engaged in defensive institutional work involving token presence and inaction so as to manage the level of dissensus. Political tactics sustained consensus on the existing institutions while not aggravating senior politicians who were sponsoring the planning process. Since Cinde was responsible for other business sectors (not only software), the organizational field was heterogeneous, and focused dissensus against the Cinde mandate within the software sector could not be mobilized, and a countersubculture was not allowed to adequately develop. Furthermore, the capitalist logic inscribed in the formal national constitution, the Washington consensus free market principles (such as embedded into the Central American free trade agreement 'CAFTA') that the government was actively pursuing, provided a firm degree of legitimacy to the Cinde mandate, which could not be countered. Intel, backed by the Costa Rican President, also acted as an important precedent legitimizing the mandate of Cinde. A summary is provided in Table 3 . 
Table 3 Timeline showing consensus and dissensus at Cinde

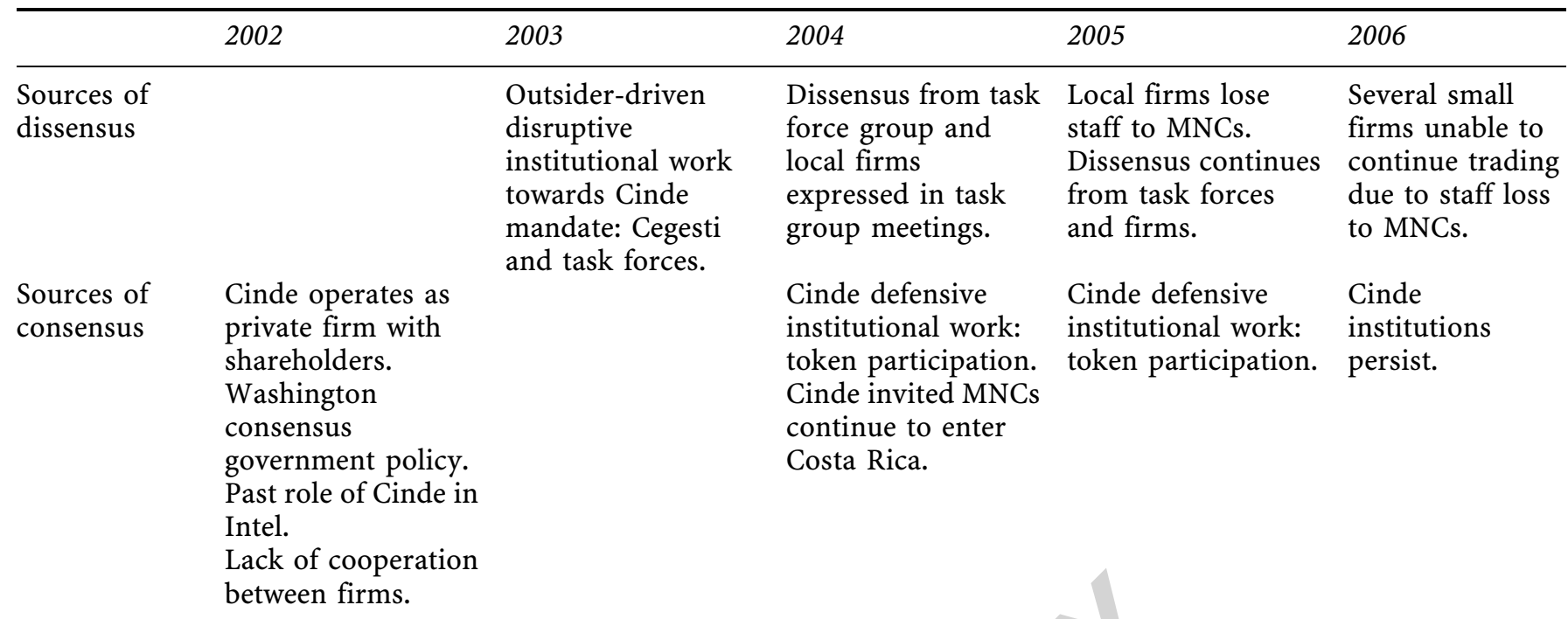

\section{Conclusions}

The two episodes described above provide insights into the process of deinstitutionalization focussing on dissensus, consensus and the political and cultural influences. We elaborate below on some of these insights.

In the Caprosoft episode, initially deinstitutionalization was not forthcoming due to the dominance of the 'wine drinking subculture' and the political means of that subculture (Caprosoft board membership) to exclude the ITES firms. However, over time due to external conditions such as the IADB funding mandate, disruptive institutional work of the outsider consultants; exposure to other country 'best practices' and internal changes in board membership, a counter-subculture emerged. Cultural traits, such as conflict avoidance and inertia, could be eventually overcome by the dissensus created by the disruptive institutional work of the emerging counter-subculture. This was not possible in the Cinde episode, in which the institutions of Cinde were 'nested' (Dacin et al., 1999) in wider institutions providing legitimacy and consensus. The outsider-driven disruptive institutional work was inadequate to generate sufficient dissensus within Cinde or in the organization field to challenge this position. Besides the institutional nesting, the defensive institutional work carried out by Cinde (presenteeism and inaction) proved to be an important tactical ploy to ward off outsider-driven attempts to create dissensus. In the Camtic case, the insider-driven dissensus was more focused in a subculture that mobilized towards desired ends. In contrast at Cinde, although considerable dissensus with regard to Cinde institutions was expressed by the task force members and among the software firms more widely, this did not extend to Cinde insiders who did not identify with the agenda for deinstitutionalization, and observed a very different set of governance criteria.

This paper makes both practical and theoretical contributions that we now discuss. Although the paper is limited by basis on a single case study, we argue that it offers deep insights and the basis of analytical generalization
(Walsham, 1995). Dealing first with the practical contributions, creating and implementing national-level software export policy represents a 'messy problem situation' (Checkland and Scholes, 1999) far removed from the typically promoted context independent critical success factors models (e.g. Carmel, 2003). Institutional theory provides tools for a systematic examination and diagnosis for action. As shown above, Cinde were reluctant to change the formal mandate and also the informal practices to accommodate processes of change, due to nestedness in national institutions of economic policy, international institutions of the 'Washington consensus' and CAFTA. This could counteract the more localized and opposing subculture as in the case of Caprosoft. We discussed in the introduction to this paper that many countries are attempting to develop software export policy. Such a nuanced understanding of the sources and mechanisms of change that institutional theory provides can be drawn upon by managers and other practitioners to understand why certain institutions prevail and others do not, and thus how and when to apply their resources. A contextualized approach provides richer practical insights into the phenomenon than the 'factors' type models of software exports industry planning (Carmel, 2003; Heeks and Nicholson, 2004), which promote the use of best practices but do not focus on the challenges of implementation and how can they be addressed. Factor models have little to contribute to implementation but implicit are assumptions of unitary homogeneous groups within organizations in which formal and informal institutions can be aligned logically and rationally to a national vision. The subculture approach to analysis emphasizes the futility of such models.

In summary, the practical contribution of this paper is derived from action research, emphasizes the importance of considering the multiplicity of institutional influences on a seemingly 'rational' strategy making process, and critiques the view that it is likely to progress harmoniously following a 'diffusion' model. Institutional theory helps to 
improve our understanding of why this may not happen. In our action research efforts, we partnered with a local firm that helped us to forge an understanding to a certain degree of some of the local institutions, which are often hidden to outsiders, and build a more nuanced and context-specific understanding about the interventions for change.

There are three major points of theoretical contribution, which we set out below. A contribution of this paper is in improving our understanding of the role of disruptive and defensive institutional work in creating or suppressing dissensus. The focussed insider-driven dissensus in the Camtic case, in contrast with the more outsider-driven and fragmented dissensus in the Cinde case, could be seen to be partially responsible for the varying deinstitutionalization outcomes. The inferences that can be drawn from studying the contrasting episodes is that insider-driven dissensus may serve to be more effective than outsider-driven efforts to drive change.

Second, we observe and illustrate the importance of nestedness (Dacin et al., 1999) in relation to deinstitutionalization processes. For Oliver, deinstitutionalization is 'the process by which the legitimacy of an established or institutionalized organizational practice erodes or discontinues' (1992: 564). We demonstrate empirically across two episodes how relative levels of nestedness in wider institutions contributes to the legitimacy of practices. Cinde institutions were nested in the free trade principles espoused by the government, whereas in the Caprosoft case the institutions were not nested in deeper legitimizing institutions outside of the Caprosoft organization and were sustained only by the parochial values of a 'wine drinking club' subculture. This could be relatively easily deinstitutionalized in the face of heightened dissensus drawing on an economic rationale of industry growth, coupled with the need to draw upon global best practices.

The third area of contribution is related to an expansion of the application of institutional theory, specifically the concepts of deinstitutionalization and persistence. We identified that the use of institutional theory in information systems is limited in providing explanations for change and why some organizations adopt radical change whereas others do not, despite experiencing similar institutional pressures. The case episodes contribute an empirical exposition of the dynamics underlying consensus and dissensus that incorporates a cultural-political analysis, a need expressed by Oliver (1992), to determine how dissensus creates institutional adjustments or erosion. From our analysis and theoretical discussion (Figure 1), we specifically contribute to understanding the effects of subcultures in the generation of dissensus contributing to deinstitutionalization process. Further, we attempt to link the 'micro with the macro' in describing how these subcultures find legitimacy of their actions in wider cultural traits, such as the tendency to avoid conflict. We have thus taken these arguments to a fine level of granularity with regard to subcultures viewed through a cultural-political perspective. This further enriches our understanding of studying influences arising from an organizational field.

The information systems domain is clearly ripe for continuing research into deinstitutionalization, as a key research area concerns the understanding of ICT enabled change. Deinstitutionalization is an important concept to understand the influences the change efforts need to confront, and how can these be addressed.

\section{Notes}

1 The four task force groups were focussed on university-private sector linkages, marketing, finance and the role of Caprosoft (the national software association).

2 Colloquial term for Costa Ricans.

\section{References}

Al-Jaghoub, S. (2004). Building a Knowledge Based Economy Using ICT for Development and the Role of the Nation State: A case study of Jordan, Unpublished Ph.D. thesis, University of Manchester.

Al-Jaghoub, S. and Westrup, C. (2003). Jordan and ICT-led Development towards a Competition State? Information Technology \& People 16(1): 93-110.

Arora, A., Arunachalam, V., Asundi, J. and Fernandes, R. (2001). The Indian Software Services Industry, Research Policy 30: 1267-1287.

Avgerou, C. (2002). Information Systems and Global Diversity, Oxford: Oxford University Press.

Baskerville, R. and Wood-Harper, A.T. (1996). A Critical Perspective on Action Research as a Method for Information Systems Research, Journal of Information Technology 11: 235-246.

Berger, P. and Luckmann, T. (1967). The Social Construction of Reality, New York: Doubleday.

Biesanz, M.H., Biesanz, R. and Biesanz, K. (1998). The Ticos: Culture and social change in Costa Rica, San Jose: Lynne Rienner Publishers.

CAMTIC (2006). The Costa Rica ICT Sector, in 3rd International Information and Communication Technologies Summit (San Jose, Costa Rica, 2006); San Jose: CAMTIC.

Carmel, C. and de Fontenay, C. (2004). Israel's Silicon Wadi: The forces behind cluster formation, in T. Bresnahan and A. Gambardella (eds.) Building HighTech Clusters Silicon Valley and Beyond, Cambridge: Cambridge University Press, pp. 40-77.

Carmel, E. (2003). Introduction to the Special Issue: The emergence of software exporting industries in dozens of developing and emerging economies, Electronic Journal of Information Systems in Developing Countries 13(1), [WWW document] http://www.ejisdc.org/ojs2/index.php/ejisdc/issue/view/ 73 (accessed 28th August 2009).

Currie, W. (2009). Contextualising the IT Artefact towards a Wider Research Agenda for Using Institutional Theory, Information Technology and People 22(1): 63-77

Checkland, P. (1991). From Framework through Experience to Learning the Essential Nature of Action Research, in H. Nissen, H. Klein and R. Hirschheim (eds.) Information Systems Research Contemporary Approaches and Emergent Traditions, Amsterdam: Elsevier, pp. 397-403.

Checkland, P. and Scholes, S.G. (1999). Soft Systems Methodology in Action, Chichester: Wiley.

Chizema, A. and Buck, T. (2006). Neo-institutional Theory and Institutional Change towards Empirical Tests on the Americanization of German Executive Pay, International Business Review 15(5): 488-504.

Dacin, M. and Dacin, P. (2008). Traditions and Institutionalised Practice: Implications for deinstitutionalization, in R. Greenwood, C. Oliver, R. Suddaby and K. Sahlin-Andersson (eds.) The Sage Handbook of Organizational Institutionalism, London: Sage.

Dacin, M., Ventresca, M. and Beal, B. (1999). The Embeddedness of Organizations Debates Dialogue \& Directions, Journal of Management 25(3): 317-356.

DiMaggio, P. and Powell, W. (1983). The Iron Cage Revisited Institutional Isomorphism and Collective Rationality in Organizational Fields, American Sociological Review 48: 147-160.

DiMaggio, P. and Powell, W. (1991). Introduction, in P. DiMaggio and W. Powell (eds.) The New Institutionalism in Organisational Analysis, Chicago: University of Chicago Press, pp. 1-38.

Duong, N. (2004). Software industry development in Vietnam, [WWW document] http//wwwiipiorg/Conferences/Hawaii_SW_Conference/ Nguyen\%20Paperpdf (accessed 20th August 2009). 
Ein-Dor, P., Myers, M. and Raman, K. (1997). IT in Three Small Developed Countries, Journal of Management Information Systems 13(4): 61-89.

Ein-Dor, P., Myers, M. and Raman, K. (2004). IT Industry Development and the Knowledge Economy: A four country study, Journal of Global Information Management 12(4): 23-49.

Erakovic, L. and Powell, M. (2006). Pathways of Changes Organizations in Transition, Public Administration 84(1): 31-58.

Farjoun, M. (2002). The Dialectics of Institutional Development in Emerging and Turbulent Fields: The history of pricing conventions in the on-line database industry, Academy of Management Journal 45(5): 848-874.

Heeks, R. (1999). Software Strategies in Developing Countries, Communications of the ACM 142(6): 15-20.

Heeks, R. and Nicholson, B. (2004). Software Export Success Factors and Strategies in Developing and Transitional Economies, Competition and Change 8(3): 267-302.

Kambhampati, U. (2002). The Software Industry and Development: The case of India, Progress in Development Studies 2(1): 23-45.

Ketelhoehn, N. and Porter, M. (2002). Building a cluster: Electronics and information technology in Costa Rica, Harvard Business School Case 9-703-422.

King, J.L., Gurbaxani, V., Kraemer, K.L., McFarlan, F.W., Raman, K.S. and Yap, C.S. (1994). Institutional Factors in Information Technology Innovation, Information Systems Research 5(2): 139-169.

Koene, B. (2006). Situated Human Agency Institutional Entrepreneurship and Institutional Change, Journal of Organizational Change Management 19(3): 365-382.

Leidner, D. and Kayworth, T. (2006). Review of Culture in Information Systems Research toward a Theory of Information Technology Culture Conflict, MIS Quarterly 30(2): 357-399.

Maguire, S. and Hardy, C. (2009). Discourse and Deinstitutionalization: The decline of DDT, Academy of Management Journal 52(1): 148-178.

Meyer, J.W. and Rowan, B. (1977). Institutionalized Organizations: Formal structure as myth and ceremony, American Journal of Sociology 83: 340-363.

Morgan, G. (1986). Images of Organization, London: Sage.

Noir, C. and Walsham, G. (2007). The Great Legitimizer: ICT as myth and ceremony in the Indian healthcare sector, Information Technology \& People 20(4): 313-333.

O'Higgins, E. (2002). Government and the Creation of the Celtic Tiger: Can management maintain the momentum? Academy of Management Executive 16(3): 104-120.

Ó Riain, S. (1997). An Offshore Silicon Valley? Competition and Change 2: $175-212$.

Oliver, C. (1992). The Antecedents of Deinstitutionalization, Organization Studies 13: 563-588.

Orlikowski, W.J. and Barley, S. (2001). Technology and Institutions: What can research on information technology and research learn from each other? MIS Quarterly 25(2): 145-165.

Rodrigues, S. (2006). The Political Dynamics of Organizational Culture in an Institutionalised Environment, Organizational Studies 27(4): 537-557.

Roberts, P. and Greenwood, R. (1997). Integrating Transaction Cost and Institutional Theories: Towards a constrained efficiency framework for understanding organizational design adoption, Academy of Management Journal 22(2): 346-373.

Robey, D. and Boudreau, M. (1999). Accounting for the Contradictory Organizational Consequences of Information Technology: Theoretical directions and methodological implications, Information Systems Research 10(2): 167-185.

Robey, D. and Holmstrom, J. (2001). Transforming Municipal Governance in Global Context: A case study of the dialectics of social change, Journal of Global Information Technology Management 4(4): 19-31.
Rorrer, A. (2006). Eroding Inequality Straddling the Margin of Tolerance, Educational Policy 20(1): 225-248.

Scott, W.R. (1987). The Adolescence of Institutional Theory, Administrative Science Quarterly 32: 493-511.

Scott, W.R. (1994). Institution and Organizations toward a Theoretical Synthesis, in W.R. Scott and J. Meyer (eds.) Institutional Environments and Organizations, Thousand Oaks: Sage, pp. 55-80.

Scott, W.R. (2001). Institutions and Organizations, Thousand Oaks: Sage.

Silva, L. and Backhouse, J. (1997). Becoming Part of the Furniture: The institutionalisation of information systems, in A.S. Lee, J. Liebenau and J.I. DeGross (eds.) Information Systems and Qualitative Research, London: Chapman \& Hall, pp. 389-414.

Silva, L. and Figueroa, E. (2002). Institutional Intervention and the Expansion of ICTs in Latin America: The case of Chile, Information Technology \& People 15(1): 8-25.

Walsham, G. (1995). The Emergence of Interpretivism in Information Systems Research, Information Systems Research 6(4): 376-394.

Walsham, G. (2002). Cross-cultural Software Production and Use: A structurational analysis, MIS Quarterly 26(4): 359-380.

Windels, P. and Christiaens, J. (2006). Management Reform in Flemish Public Centres for Social Welfare: Examining organizational change, Local Government Studies 32(4): 389-411.

World Bank (2002). Information and communication technologies: a World Bank strategy, [WWW document] http//siteresourcesworldbankorg/ INTINFNETWORK/Resources/ictpdf (accessed 28th August 2009).

\section{About the authors}

Brian Nicholson is a senior lecturer at Manchester Business School. Since 1995, he has been involved in research and consultancy in the areas of global outsourcing and software industry development in developed and developing countries. He is Co-director of the Centre for Development Informatics at University of Manchester. His current research area includes corporate social and environmental responsibility and management of business process outsourcing. His research has been published in a book (coauthored with Sundeep Sahay) 'Global IT Outsourcing' (Cambridge University Press, 2003) and in leading information systems, development and business journals.

Sundeep Sahay is a professor at the Department of Informatics at the University of Oslo, Norway. $\mathrm{He}$ is actively involved in researching social, organizational and managerial implications of information systems, both in developed and developing countries. His current research areas include health information systems and issues relating to global software organizations. Sundeep has published extensively both in leading information systems and organization studies journals. Sundeep is actively involved in action research on the issues of global outsourcing and health information systems recently in Tajikistan and India. 